NBER WORKING PAPER SERIES

\title{
FACTOR PRICE EQUALIZATION IN THE UK?
}

\author{
Andrew B. Bernard \\ Stephen Redding \\ Peter K. Schott \\ Helen Simpson
}

Working Paper 9052

http://www.nber.org/papers/w9052

\author{
NATIONAL BUREAU OF ECONOMIC RESEARCH \\ 1050 Massachusetts Avenue \\ Cambridge, MA 02138 \\ July 2002
}

This paper was produced under contract to the Office for National Statistics. We are grateful to Richard Blundell, Donald Davis, Gilles Duranton, Rachel Griffith, Costas Meghir, Matthew Slaughter, Tony Venables, David Weinstein, and seminar participants at the CEPR Erwit Conference, Columbia University, Dartmouth College, the Institute for Fiscal Studies, and the London School of Economics for helpful comments. Stephen Redding's research was financed by the ESRC-funded Centre for Economic Performance at the London School of Economics. Helen Simpson's research was financed by the ESRC-funded Centre for the Microeconomic Analysis of Public Policy at the Institute for Fiscal Studies. Any opinions, results, and errors are the responsibility of the authors. The views expressed herein are those of the authors and not necessarily those of the National Bureau of Economic Research.

(C) 2002 by Andrew B. Bernard, Stephen Redding, Peter K. Schott and Helen Simpson. All rights reserved. Short sections of text, not to exceed two paragraphs, may be quoted without explicit permission provided that full credit, including $(\mathcal{C}$ notice, is given to the source. 
Factor Price Equalization in the UK?

Andrew B. Bernard, Stephen Redding, Peter K. Schott and Helen Simpson

NBER Working Paper No. 9052

July 2002

JEL No. F1, C1, J3

\begin{abstract}
This paper develops a general test of factor price equalization that is robust to unobserved regional productivity differences, unobserved region-industry factor quality differences and variation in production technology across industries. We test relative factor price equalization across regions of the UK. Although the UK is small and densely-populated, we find evidence of statistically significant and economically important departures from relative factor price equalization. Our estimates suggest three distinct relative factor price areas with a clear spatial structure. We explore explanations for these findings, including multiple cones of diversification, region-industry technology differences, agglomeration and increasing returns to scale.
\end{abstract}

Andrew B. Bernard

Tuck School of Business

100 Tuck Hall

Hanover, NH 03755

and NBER

Tel: 6036460302

Fax: 6036460995

Email: andrew.b.bernard@dartmouth.edu

Peter K. Schott

Yale School of Management

135 Prospect Street

New Haven, CT 06520-8200

and NBER

E-mail: peter.schott@yale.edu
Stephen Redding

Department of Economics

London School of Economics

Houghton Street

London

WC2A 2AE

United Kingdom

E-mail: s.j.redding@1se.ac.uk

Helen Simpson

Institute for Fiscal Studies

7 Ridgmount Street

London

WC1E 7AE

United Kingdom

E-mail: hsimpson@ifs.org.uk 


\section{Introduction}

Do factor prices vary across regions within a country? This question is of fundamental importance to governments pursuing policies for regional development, firms choosing plant locations, and workers deciding where to live. Economic theory suggests two powerful mechanisms promoting factor price convergence across regions and countries - goods trade and factor mobility. Within a country, goods markets are more highly integrated, and factors of production are more mobile, than they are across countries. As a result, factor price equalization, to the extent it exists anywhere, is more likely to occur within nations than internationally. We develop very general tests of absolute and relative factor price equalization and apply them to regions within the United Kingdom. The UK is a particularly well-suited focus for such tests given its small geographic area and high population density, conditions which promote output and factor market integration.

Absolute factor price equality implies that identical factors of production are paid the same wage across regions. Relative factor price equality, on the other hand, allows absolute wages to vary so long as relative wages (i.e. the skill premium) remain constant. An obvious potential explanation for a violation in absolute factor price equality is the existence of regional Hicks-neutral productivity differences: regions with higher Hicks-neutral productivity can offer higher wages to both skilled and unskilled workers even while relative wages remain uniform.

Rejection of factor price equality can also arise for more complicated reasons. For example, both absolute and relative factor price equality can fail due to unobserved variation in regional factor quality. Analyzing the effect of such variation on output and wages has a long history in the international trade literature, including the classic paper by Leontief (1953) and the more recent cross-country study by Trefler (1993). A key advantage of the methodology that we develop is its robustness to unobserved differences in factor quality. Indeed, our tests control for factor quality differences across pairs of regions and industries.

Our approach is based upon extremely general conditions for producer equilibrium and builds upon techniques developed by Bernard and Schott (2001) to test for factor price equality in the US. We generalize that theo-

retical framework from the case of the CES production technology to any 
constant returns to scale technology, to allow for unobserved factor quality differences that are region-industry specific rather than just region-specific, and to the case of imperfect competition. Our methodology exploits the fact that, although an empirical researcher will not typically observe factor quality or quality-adjusted factor prices, observed factor prices contain information about the quality of observed factors when firms minimize costs. Our approach does not make any assumptions regarding the preferences and costs of living faced by different types of workers. As a result, it is robust to unobserved variation in consumer price indices specific to types of workers or locations. Nonetheless, the analysis has implications for the value of real wages and the degree of factor mobility across locations.

Though our technique is applicable to any number of factors of production, we focus here on the wages of skilled versus unskilled labour. We find strong evidence against both absolute and relative factor price equality in the UK. This rejection exists across both coarsely-aggregated Administrative Regions and much more finely-defined Postcode Areas, which approximate local labour markets. Estimated differences in quality-adjusted factor prices across the UK are highly statistically significant and quantitatively important.

We explore a number of potential explanations for deviations from factor price equality. One subset of explanations provide intuition for the failure of factor price equality. Among these are the existence of multiple Heckscher-Ohlin cones of diversification within the UK and several aspects of the new economic geography. We also consider how data-related issues can induce a rejection of the null hypothesis. In each case, we highlight additional empirical implications which can be pursued.

Existing tests of factor price equality, including Cunat (2001), Debaere and Demiroglu (1997), Repetto and Ventura (1998), and Schott (2001a, $2001 b$ ), have focused on the variation of wages across countries or the existence of multiple cones of diversification in international production data. Other studies, including Davis et al. (1997), Bernstein and Weinstein (2002) and Hanson and Slaughter (2002), have looked for evidence of factor price equalization across either Japanese prefectures or US states. Further research on the spatial variation of productivity and factor prices in the United States includes Ciccone and Hall (1996), Ciccone (2001), and Hanson (1998). With respect to the UK, recent work by Cameron and 
Muellbauer (2000,2001), Duranton and Monastiriotis (2001), Gosling et al. (1996), HM Treasury (2001), and Machin (1996) has examined the extent of regional earnings and productivity differences across regions. Haskel and Slaughter (2001) analyze the impact of international trade on wage inequality at the level of the United Kingdom as a whole. Though some of this research has found evidence consistent with a violation of factor price equality, none of the studies has controlled for the sort of variation in factor quality and technology differences that we find so important. Our study is also the first to examine the finely defined UK Postcodes in addition to the coarsely aggregated Administrative Regions.

The paper is structured as follows. Section 2 introduces the general theoretical framework and derives empirical tests for absolute and relative factor price equalization. Section 3 describes the data. Section 4 discusses the econometric specification, and Section 5 presents the empirical results. Section 6 examines a number of potential explanations for violations of absolute and relative factor price equality. Section 7 concludes.

\section{Theoretical Framework}

\subsection{Production}

We consider a very general specification of the production environment facing firms that allows for both perfect competition and imperfect competition, as well as variation in goods prices, technology, and factor quality across regions and industries. Regions are denoted by $r$, industries by $j$, and time by $t$. Throughout the exposition, subscripts are used to refer to industries or regions and superscripts to refer to factors of production or pairs of factors.

In each industry-region, firms choose output and employment of factors of production to maximize profits subject to a constant returns to scale production technology,

$$
\begin{gathered}
\Pi_{r j}=v_{r j}\left(Y_{r j}\right) Y_{r j}-w_{r}^{P} P_{r j}-w_{r}^{N} N_{r j}-w_{r}^{K} K_{r j} \\
Y_{r j}=A_{r j} F_{j}\left(P_{r j}, N_{r j}, K_{r j}\right)
\end{gathered}
$$

where $v$ is the output price, $P$ is employment of quality-adjusted production workers, $N$ is employment of quality-adjusted non-production workers, and 
$K$ is employment of quality-adjusted physical capital. The factor prices $w_{r}^{P}$, $w_{r}^{N}$, and $w_{r}^{K}$ are per quality-adjusted unit of a factor of production.

In this specification, firms may either act as price-takers in product markets (perfect competition) or choose prices subject to a downward sloping demand curve (imperfect competition). They behave as price-takers in factor markets. Although the main exposition here assumes constant returns to scale, later sections and an appendix introduce increasing returns to scale and discuss their implications for absolute and relative factor prices.

For clarity, we have concentrated here on the three factors of production for which data are available. However, the analysis makes no assumptions about the relative number of goods and factors of production. We present a general methodology for testing factor price equalization given data on factor prices, employment, and output for arbitrary numbers of goods and arbitrary numbers of factors of production.

\subsection{Quality-adjusted and Observed Factors}

If it were possible to observe quality-adjusted factor prices and quantities in the data, we could test for factor price equalization directly. In practice, factor quality is not observed and we allow it to vary in a completely general way across both regions and industries. Quality-adjusted employments of factors of production will be related to their observed values as follows,

$$
P_{r j}=\theta_{r j}^{P} \tilde{P}_{r j}, \quad N_{r j}=\theta_{r j}^{N} \tilde{N}_{r j}, \quad K_{r j}=\theta_{r j}^{K} \tilde{K}_{r j} .
$$

where a tilde above a variable indicates that it is an observed value. Observed factor prices will be related to quality-adjusted values according to,

$$
\tilde{w}_{r j}^{P}=\theta_{r j}^{P} w_{r}^{P}, \quad \tilde{w}_{r j}^{N}=\theta_{r j}^{N} w_{r}^{N}, \quad \tilde{w}_{r j}^{K}=\theta_{r j}^{K} w_{r}^{K} .
$$

\subsection{Cost Minimization}

Our tests for factor price equality are direct implications of firms' cost minimization (hence the property that they hold under both perfect and imperfect competition). The cost function dual associated with the production technology is,

$$
B_{r j}=A_{r j}^{-1} \Gamma_{j}\left(w_{r}^{P}, w_{r}^{N}, w_{r}^{K}\right) Y_{r j} .
$$


Demands for quality-adjusted factors of production may be obtained using Shepherd's Lemma,

$$
P_{r j}=A_{r j}^{-1} Y_{r j} \frac{\partial \Gamma_{j}(\cdot)}{\partial w_{r}^{P}}, \quad N_{r j}=A_{r j}^{-1} Y_{r j} \frac{\partial \Gamma_{j}(\cdot)}{\partial w_{r}^{N}}, \quad K_{r j}=A_{r j}^{-1} Y_{r j} \frac{\partial \Gamma_{j}(\cdot)}{\partial w_{r}^{K}} .
$$

Dividing one first-order condition by another, we arrive at an expression for relative demand for any two quality-adjusted factors of production. Thus, for non-production (skilled) and production (unskilled) workers we have,

$$
\frac{N_{r j}}{P_{r j}}=\frac{\partial \Gamma_{j}(\cdot) / \partial w_{r}^{N}}{\partial \Gamma_{j}(\cdot) / \partial w_{r}^{P}}
$$

Using the relationship between quality-adjusted and observed values in (3), this implies the following relative demand for observed factors of production,

$$
\frac{\tilde{N}_{r j}}{\tilde{P}_{r j}}=\frac{\theta_{r j}^{P}}{\theta_{r j}^{N}} \frac{\partial \Gamma_{j}(\cdot) / \partial w_{r}^{N}}{\partial \Gamma_{j}(\cdot) / \partial w_{r}^{P}} .
$$

\subsection{Regional Factor Price Differences}

In principle, the price of each quality-adjusted factor of production may vary across regions. To capture this variation, we make use of the fact that any factor price difference between a region $r$ and another reference region $s$ can be decomposed into a component common to all factors of production $\left(\lambda_{r s}\right)$ and a factor-specific component $\left(\gamma_{r s}^{z}, z \in\{P, N, K\}\right)$. For example,

$$
\begin{aligned}
w_{r}^{N} & =\delta_{r s}^{N} w_{s}^{N}=\lambda_{r s} \gamma_{r s}^{N} w_{s}^{N} \\
w_{r}^{P} & =\delta_{r s}^{P} w_{s}^{P}=\lambda_{r s} \gamma_{r s}^{P} w_{s}^{P} \\
w_{r}^{K} & =\delta_{r s}^{K} w_{s}^{K}=\lambda_{r s} w_{s}^{K}
\end{aligned}
$$

where, in the example above, we have normalized the common component using capital price differences across regions $\left(\lambda_{r s}=\delta_{r s}^{K}\right.$ and $\left.\gamma_{r s}^{N}=\delta_{r s}^{N} / \delta_{r s}^{K}\right)$. Other normalizations are clearly possible and the analysis is invariant to which is chosen.

Since it is hard to accurately measure the real user cost of capital at the regional level, we focus in our empirical work on the absolute and relative 
wages of non-production and production workers. Under the null hypothesis of factor price equalization, all factor prices are equalized. A rejection of relative factor price equalization for any pair of factors will therefore be sufficient for a rejection of the null hypothesis. In principle, the analysis here may be undertaken for all combinations of factors of production.

\subsection{Relative Factor Price Equalization (RFPE)}

\subsubsection{Null Hypothesis}

Our most general test of factor price equalization is concerned with relative factor prices, and allows for both unobserved variation in factor quality across region-industry pairs and neutral technology differences. The null hypothesis of Relative Factor Price Equalization (RFPE) may be formalized as:

$$
\left(H_{0}: \mathrm{RFPE}\right), \quad \gamma_{r s}^{z}=1 \forall z, \quad \frac{w_{r}^{N}}{w_{r}^{P}}=\frac{w_{s}^{N}}{w_{s}^{P}} .
$$

The potential existence of unobserved factor quality differences across re-

gions within an industry $\left(\theta_{r j}^{N} \neq \theta_{s j}^{N}\right.$ and/or $\theta_{r j}^{P} \neq \theta_{s j}^{P}$ in equation 4) means that we cannot test this hypothesis directly using observed relative wages. However, we show below that RFPE implies the equalization of observed relative wage bills across regions and that this prediction is robust to unobserved factor quality differences. Without loss of generality, we choose region $s$ as the reference region for measuring factor quality differences so that,

$$
\theta_{s j}^{N}=1, \quad \theta_{s j}^{P}=1, \quad \forall j .
$$

Under the null hypothesis of RFPE, the values of observed relative wages in the two regions are given by,

$$
\frac{\tilde{w}_{r}^{N}}{\tilde{w}_{r}^{P}}=\frac{\theta_{r j}^{N}}{\theta_{r j}^{P}} \frac{\tilde{w}_{s}^{N}}{\tilde{w}_{s}^{P}} .
$$

Observed values of relative employment in the two regions may be obtained using equation (8). Under RFPE, quality-adjusted factor prices differ across regions by a component $\lambda_{r s}$ that is common across all factor prices. Homogeneity of degree 1 of the cost function implies that the derivatives $\partial \Gamma_{j} / \partial w_{r}^{z}$ 
are homogenous of degree 0 in factor prices. Thus,

$$
\frac{\partial \Gamma_{j}\left(w_{r}^{P}, w_{r}^{N}, w_{r}^{K}\right)}{\partial w_{r}^{z}}=\frac{\partial \Gamma_{j}\left(\lambda_{r s} w_{s}^{P}, \lambda_{r s} w_{s}^{N}, \lambda_{r s} w_{s}^{K}\right)}{\partial\left(\lambda_{r s} w_{s}^{z}\right)}=\frac{\partial \Gamma_{j}\left(w_{s}^{P}, w_{s}^{N}, w_{s}^{K}\right)}{\partial w_{s}^{z}}, \quad \forall z .
$$

It follows immediately from equation (7) that, with identical quality-adjusted relative factor prices, regions will employ quality-adjusted factors of production in the same proportions. Using the relationship between observed and quality-adjusted values, observed relative employment will vary across regions in direct proportion to factor quality differences (from equation $(8)$ ),

$$
\frac{\tilde{N}_{r j}}{\tilde{P}_{r j}}=\frac{\theta_{r j}^{P}}{\theta_{r j}^{N}} \frac{\tilde{N}_{s j}}{\tilde{P}_{s j}} .
$$

Multiplying the expressions for observed relative factor prices and observed relative employments, the terms in unobserved factor quality cancel. We obtain the empirical prediction that, under the null hypothesis of RFPE, the ratio of the observed wage bills (wbill) of non-production to production workers is equalized across regions:

$$
\left(H_{0}: \mathrm{RFPE}\right), \quad \frac{{\widetilde{\operatorname{wbill}_{r j}}}^{N}}{\widetilde{\text { wbill }_{r j}^{P}}}=\frac{{\widetilde{\operatorname{wbill}_{s j}}}^{N}}{{\widetilde{\operatorname{wbill}_{s j}}}^{P}} .
$$

\subsubsection{Alternative Hypothesis}

The alternative hypothesis is that relative quality-adjusted wages vary across regions. This variation is reflected in the factor-specific component of factor price differences $\left(\gamma_{r s}^{z}\right)$ :

$$
\left(H_{1}: \text { non-RFPE }\right) \quad \gamma_{r s}^{z} \neq 1, \quad \frac{w_{r}^{N}}{w_{r}^{P}}=\frac{\gamma_{r s}^{N}}{\gamma_{r s}^{P}} \frac{w_{s}^{N}}{w_{s}^{P}}=\gamma_{r s}^{N P} \frac{w_{s}^{N}}{w_{s}^{P}} .
$$

Observed values of relative wages in the two regions are thus,

$$
\frac{\tilde{w}_{r}^{N}}{\tilde{w}_{r}^{P}}=\gamma_{r s}^{N P} \frac{\theta_{r j}^{N}}{\theta_{r j}^{P}} \frac{\tilde{w}_{s}^{N}}{\tilde{w}_{s}^{P}}
$$


Observed values of relative employment in the two regions may again be obtained from equation (8),

$$
\frac{\tilde{N}_{r j}}{\tilde{P}_{r j}}=\frac{\theta_{r j}^{P}}{\theta_{r j}^{N}}\left(\frac{\partial \Gamma_{j}(\cdot) / \partial w_{r}^{N}}{\partial \Gamma_{j}(\cdot) / \partial w_{r}^{P}}\right)\left(\frac{\partial \Gamma_{j}(\cdot) / \partial w_{s}^{P}}{\partial \Gamma_{j}(\cdot) / \partial w_{s}^{N}}\right) \frac{\tilde{N}_{s j}}{\tilde{P}_{s j}} .
$$

Multiplying the expressions for observed relative factor prices and observed relative employments, the terms in unobserved factor quality again cancel. The ratio of the observed wage bills of non-production to production workers under the alternative of non-relative factor price equalization is thus:

$$
\begin{aligned}
& \frac{{\widetilde{\text { wbill }_{r j}}}^{N}}{\widetilde{\text { wbill }_{r j}^{P}}}=\gamma_{r s}^{N P}\left(\frac{\partial \Gamma_{j}(\cdot) / \partial w_{r}^{N}}{\partial \Gamma_{j}(\cdot) / \partial w_{r}^{P}}\right)\left(\frac{\partial \Gamma_{j}(\cdot) / \partial w_{s}^{P}}{\partial \Gamma_{j}(\cdot) / \partial w_{s}^{N}}\right) \frac{{\widetilde{w_{b i l l}}}_{s j}^{N}}{\widetilde{\text { wbill }_{s j}^{P}}} .
\end{aligned}
$$

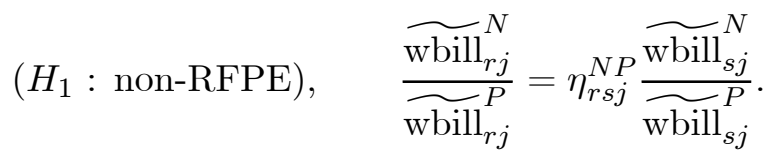

Appendix A shows that with a CES production technology, which is itself a fairly flexible functional form, the expression in equation (18) simplifies to,

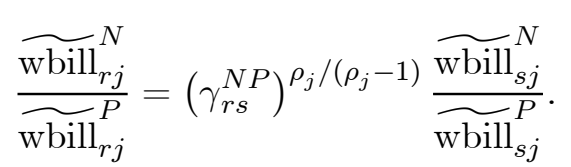

Together equations (14) and (19) provide the basis for a test of the null hypothesis of RFPE that is robust to unobserved region-industry variation in factor quality. RFPE implies a testable parameter restriction in equation (19), namely $\eta_{r s j}^{N P}=1$, which we exploit in our empirical work below.

Note that $\eta_{r s j}^{N P} \neq 1$ is sufficient to reject RFPE, but not necessary. This is seen most clearly from equation (20), where even if $\gamma_{r s}^{N P} \neq 1$ (so that quality-adjusted relative wages are not equalized), the parameter $\eta_{r s j}^{N P}=$ $\left(\gamma_{r s}^{N P}\right)^{\rho_{j} /\left(\rho_{j}-1\right)}$ will still equal 1 for the special case of a Cobb-Douglas production technology $\left(\rho_{j}=0\right)$. This is consistent with our empirical approach. We test the null hypothesis $\eta_{r s j}^{N P}=1$ and, in so far as this hypothesis is rejected, this is sufficient for us to reject RFPE. Indeed, the fact that $\left(\gamma_{r s}^{N P}\right)^{\rho_{j} /\left(\rho_{j}-1\right)}$ is close to 1 for $\rho_{j}$ close to 0 actually makes it harder for us to reject the null hypothesis and strengthens any finding of a rejection of RFPE. 


\subsection{Absolute Factor Price Equalization (AFPE)}

Also of potential interest is the question whether the absolute level of factor prices is equalized across locations. In order to control for unobserved factor quality, we once more make use of the result demonstrated above that, multiplying observed wages by observed employment levels, terms in factor quality cancel.

To test absolute factor price equalization (AFPE) we analyze variation across regions in the share of total payments to a factor of production in output. We demonstrate this for non-production workers; the analysis for other factors of production is analogous. Observed employment of non-production workers may be obtained from equations (6) and (3). Multiplying observed employment by observed wages and dividing by output, we obtain,

$$
\frac{\tilde{w}_{r j}^{N} \tilde{N}_{r j}}{Y_{r j}}=\frac{w_{r}^{N} N_{r j}}{Y_{r j}}=\left(\theta_{r j}^{N} w_{r}^{N}\right) \frac{1}{\theta_{r j}^{N}} A_{r j}^{-1} \frac{\partial \Gamma_{j}(\cdot)}{\partial w_{r}^{N}} .
$$

Under the null hypothesis of AFPE, quality-adjusted wages are equalized across regions $\left(w_{r}^{N}=w_{s}^{N}\right)$ and observed wages vary in direct proportion to unobserved factor quality $\left(\tilde{w}_{r j}^{N}=\theta_{r j}^{N} w_{s}^{N}\right)$, where we again choose region $s$ as a reference region so that $\theta_{s j}=1 \forall j$. The equalization of the absolute level of factor prices requires identical production technologies across regions and industries $\left(A_{r j}=A_{s j}\right)$. Using this in equation (21), it follows that, under the null hypothesis of AFPE, factor shares are equalized across regions:

$$
\left(H_{0}: \mathrm{AFPE}\right), \quad \frac{w_{r}^{N} N_{r j}}{Y_{r j}}=\frac{w_{s}^{N} N_{s j}}{Y_{r j}} .
$$

Under the alternative hypothesis of non-AFPE, technical efficiency may vary across region-industry pairs and regions may be characterized by different equilibrium factor prices. In this case, from equation (22), factor shares in the two regions are related as follows:

$$
\left(H_{1}: \text { non-AFPE }\right), \quad \frac{w_{r}^{N} N_{r j}}{Y_{r j}}=\gamma_{r s}^{N}\left(\frac{A_{s j}}{A_{r j}}\right)\left(\frac{\partial \Gamma_{j}(\cdot) / \partial w_{r}^{N}}{\partial \Gamma_{j}(\cdot) / \partial w_{s}^{N}}\right)\left(\frac{w_{s}^{N} N_{s j}}{Y_{s j}}\right) .
$$

Together, equations (22) and (23) provide the basis for a test of the null hypothesis of AFPE, with AFPE implying a testable parameter restriction 
in equation (23). In the rest of the paper, we focus on the test for relative factor price equalization derived above.

\subsection{Diagrammatic Representation of Producer Equilibrium}

To provide some further economic intuition for the tests, this section complements the formal analysis above with a graphical representation of producer equilibrium using a Lerner (1952) diagram. There are two regions $A$ and $B$, each of which is endowed with skilled labour $(N)$ and unskilled labour $(P)$ in quantities indicated by the endowment points $E_{A}$ and $E_{B}$. Figure 1 considers an example with three goods: skilled labourintensive Computers, unskilled labour-intensive Textiles, and intermediate skill-intensity Machinery. The production technology is characterized by the unit value isoquants for the three sectors and, for simplicity and without loss of generality, the figures are drawn for the case of Leontief or fixed unit input requirement technologies. The analysis is directly analogous for technologies with unit input requirements that vary with relative factor prices.

Even if the regions face common commodity prices and have identical technologies, sufficiently large differences in endowments will induce them to specialize in different mixes of goods with different equilibrium relative factor prices. The skilled abundant region $(A)$ produces skilled-labour intensive Computers and Machinery, while the unskilled abundant region $(B)$ specializes in Machinery and unskilled-intensive Textiles. Each region lies within a different cone of diversification, where the word 'cone' refers to the set of endowment vectors that select the same set of goods of produced.

The relative wage of skilled workers is lower in the skilled labour abundant region so that, as one looks across regions in different cones of diversification, the relative wage of skilled workers falls with their relative factor abundance. Production structure overlaps in the good with intermediate factor intensity (Machinery). And, with technologies characterized by variable unit input requirements (not shown in the figure), this overlapping good will be produced using different factor intensities in the two regions.

Other potential explanations for violations of relative factor price equalization include non-neutral technology differences across regions, regional variation in goods prices due to transport costs that differ systematically 
across industries, increasing returns to scale, as well as non-traded goods and variation in the amenities provided by different regions. All of these explanations are encompassed by the theoretical framework of the previous section and can be shown diagrammatically using analogues of Figure 1. We return to consider these explanations in detail in the empirical discussion below.

\section{Data Description}

Our data source is the United Kingdom's Annual Respondents Database (ARD). Basic information on the population of establishments in the production sector is available during 1980-98, including employment, location, ownership, and industry. More detailed information is available for a sample of these establishments, including output, investment, intermediate inputs, employment, and wages. ${ }^{1}$ This sample includes around 13000 establishments per year, and is comprised of the population of establishments with 100 or more employees together with a sample of smaller establishments. ${ }^{2}$ As our methodology requires information on wages and employment, we work with the sampled data. In the robustness section, we demonstrate that the results are not driven by any resulting sample selection bias.

In the empirical analysis, we focus on the manufacturing sector for which data are available. Under the null hypothesis of RFPE, relative wage bills should be equalized in all sectors of the economy. A rejection of the null hypothesis for manufacturing is thus sufficient for a violation of RFPE. For skilled workers we use data on Administrative, Technical, and

\footnotetext{
${ }^{1}$ ARD establishments correspond roughly to a 'line of business'. Establishments are potentially more disaggregate than firms, i.e. some firms are single establishments while others consist of several establishments. Establishments are more aggregate than plants, i.e. some establishments consist of a single plant, while others include several. As a result, an establishment's plants may be located in more than one region. Such overlap reduces spatial variation in wages, employment, and wage bills in our data, making it more difficult to reject the null hypothesis of RFPE. As a check on the empirical results, we perform several robustness tests in section 5.2 ..

${ }^{2}$ For the years that we consider (1992 and 1986), the sampling threshold is 100 employees. The ARD only contains information on production activity. Other non-production activities such as headquarter services and research and development (R\&D) are excluded. For further discussion of the ARD data, see Devereux et al. (1999), Disney et al. (2000), Duranton and Overman (2002), and Griffith (1999).
} 
Clerical Workers (non-production workers), and for unskilled workers we use information on Operatives (production workers). These are widely-used measures of skills in the existing trade and labour market literatures (see for example Berman et al. 1998 and Lawrence and Slaughter 1993) and the only measures available in the ARD data. The existing literature typically finds a high correlation between these occupation-based measures of skills and those based on educational attainment (see in particular Machin and Van Reenen 1998). Furthermore, a key advantage of our methodology is that it explicitly controls for any unobserved variation in the quality of non-production and production workers across both regions and industries.

The United Kingdom's Labour Force Survey (LFS) does report some information on the wages and employment by region according to an educational attainment-based definition of skills. A central advantage of the ARD over this alternative data source is the detailed level of industrial disaggregation. The LFS reports information only for 2 and 3-digit industries compared with 4-digit industries in the ARD. Furthermore, because the LFS is survey-based, cell sizes for even 2 and 3-digit industries in the highly disaggregated geographical regions considered here may be very small. ${ }^{3}$ The ARD yields consistent information on the wages and employment of skilled and unskilled workers across regions of the United Kingdom within highly disaggregated industries.

These aspects of the data are important because our empirical approach focuses on variation in relative wages within industries. One potential explanation for relative wage differences across regions within an industry is that the analysis is undertaken at too high a level of aggregation. The composition of an industry may vary across regions (for example, a 2-digit sector may consist of different 4-digit sub-sectors across regions). In general, tests of relative factor price equality should employ the most disaggregate industry data available.

We examine spatial variation in relative wages, employment, and wage bill levels at two levels of geographical disaggregation. First, we consider 10 Administrative Regions of the United Kingdom. ${ }^{4}$ This enables us to

\footnotetext{
${ }^{3} \mathrm{An}$ additional problem with the LFS is that the information is reported on a place of residence rather than place of work basis.

${ }^{4}$ Northern Ireland is excluded from the analysis because the data are collected separately and there is only one Postcode Area for the entire of Northern Ireland.
} 
analyze the broad pattern of spatial variation and allows the results of our methodology to be compared with existing studies which have focused on Administrative Regions. Second, we examine variation across the 100+ Postcode Areas listed in Table 1. These regions are based around towns and correspond approximately to commuting patterns and local labour market areas. Examples include Aberdeen, Birmingham, and Manchester. We aggregate the 8 postcode areas in Central London to form a single geographical region, as is consistent with commuting patterns. These data provide a rich source of information on spatial variation in factor prices within the United Kingdom, and enable us to examine whether factor price variation is greater within or across Administrative Regions.

Information on Postcode Areas is only available in the ARD from 1985 onwards; separate data on non-production and production workers ceases to be collected after 1995; and there is a change in the United Kingdom's Industrial Classification after 1992. In our main specification, we examine spatial variation in relative wages, employment, and wage bills for 1992. As a robustness test, we also report results for 1986. To the extent that we find persistent differences in quality-adjusted relative wages across UK regions for years that are at such different stages of the UK business cycle, we have evidence of systematic departures from RFPE that are not driven by idiosyncratic shocks to regions or business cycle fluctuations. In practice it may take time for firms to adjust some factors of production such as physical capital, and analyzing two separate points in time also provides evidence that the results are not driven by out of equilibrium physical capital stocks in any one year.

Establishments themselves will be subject to idiosyncratic shocks and there is likely to be measurement error in establishment-level data that may be large in any one year. Therefore, in our empirical analysis we aggregate establishments in each region to the level of approximately 200 4-digit manufacturing industries. We exclude all industries classified as 'other manufacturing' since these are heterogeneous categories and may include different sub-industries in different regions. The null hypothesis of RFPE predicts the equalization of relative wage bills across regions within each 4-digit industry. This yields approximately 1400 region-industry observations for Administrative Regions and over 5000 region-industry observations for Postcode Areas. 


\section{Econometric Specification}

In Section 2, we showed that, under the null of RFPE, the ratio of the non-production workers' wage bill to the production workers' wage bill will be the same across regions within an industry. This implies that, for an industry $j$, each region's relative wage bill should equal the value for the United Kingdom as a whole,

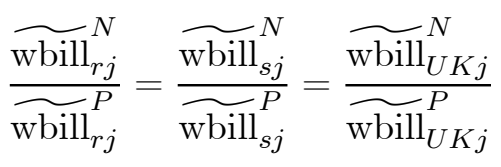

The simplest test of the null hypothesis is therefore to regress the ratio of wage bills for region $r$ relative to the ratio for the UK as a whole on set of region dummies,

$$
\ln \left(\frac{R W B_{r j}^{N P}}{R W B_{U K j}^{N P}}\right)=\sum_{r} \alpha_{r}^{N P} d_{r}+\varepsilon_{r j}^{N P}
$$

where $R W B_{r j}^{N P}$ denotes the relative wage bill in industry $j$ and region $r$ for non-production workers and production workers $\left(R W B_{r j}^{N P}=\right.$ wage bill ${ }_{r j}^{N} /$ wage $\left.\operatorname{bill}_{r j}^{P}\right) ; R W B_{U K j}^{N P}$ is the corresponding relative wage bill for the UK as a whole; and the $\alpha_{r}^{N P}$ correspond to the coefficients on the regional dummies $d_{r}$. When defining the relative wage bill for the UK as a whole, we exclude the own region $r$. Under the null hypothesis of RFPE, $\alpha_{r}^{N P}=0$ for all regions and factor pairs, and a test of whether the $\alpha_{r}^{N P}$ are jointly equal to zero therefore provides a test of RFPE.

The regression in equation (25) corresponds to a differences in means test. We choose the UK as a whole as a base region and test RFPE by comparing the relative wage bill for an industry $j$ across all regions $r$ to the value for the UK as a whole in the same industry. We also test RFPE by estimating equation (19) for all industry and region-pair combinations. That is, we begin by choosing a region $s$ to be the base $\left(\gamma_{s}^{N P}=1\right)$ and run an analogous regression to equation (25),

$$
\ln \left(\frac{R W B_{r j}^{N P}}{R W B_{s j}^{N P}}\right)=\sum_{r} \alpha_{r s}^{N P} d_{r}+\varepsilon_{r s j}^{N P}
$$


A test of whether the $\alpha_{r s}^{N P}$ are jointly equal to zero provides a test of the null hypothesis of RFPE. Rejecting $\alpha_{r s}^{N P}=0$ is sufficient to reject the null hypothesis of RFPE, and any pair of regions $r$ and $r^{\prime}$ face the same relative factor prices if $\alpha_{r s}^{N P}=\alpha_{r^{\prime} s}^{N P}$. Equation (26) is then estimated for all possible choices of base region $s$.

Although regions have the same relative wage bills under the null hypothesis of RFPE (hence $\alpha_{r s}^{N P}=0$ ), the theoretical analysis of Section 2 suggests that, under the alternative hypothesis, the coefficient on the regional dummies $\left(\eta_{r s}^{N P}\right.$ in equation 19 and $\alpha_{r s}^{N P}$ in equations 25 and 26) may vary across industries. With a constant elasticity of substitution (CES) production technology, this cross-industry variation is associated with different elasticities of substitution between skilled and unskilled workers (equation $20)$.

We have no strong priors on how the elasticity of substitution between different types of labour $\left(\rho_{j}\right)$ or other features of the operator $\Gamma_{j}$ in the cost function $\left(B_{r j}\right)$ vary across industries, and therefore we pool observations across industries. Since under the null hypothesis $\alpha_{r s j}^{N P}=0$ for all industries $j$, a finding of statistically significant coefficients on the regional dummies when pooling observations is sufficient to reject RFPE.

Under the assumption of a CES production technology and choosing a value for the elasticity of substitution $\sigma$ and hence $\rho=1-1 / \sigma$, the estimated coefficients on the regional dummies may be used to derive implied quality-adjusted relative wage differences across regions (equation 20). Comparing these estimates of quality-adjusted wage differences with actual values for relative wages, we can also derive implied differences in the relative quality of skilled and unskilled workers across regions and industries $\left(\theta_{r j}^{N} / \theta_{r j}^{P}\right.$ in equation 16$)$.

For a given value of the elasticity of substitution between skilled and unskilled workers, we are thus able to obtain estimates of the extent to which actual relative wage differences across regions correspond to true differences in quality-adjusted relative wages or are instead explained by unobserved variation in factor quality.

Note that equations (25) and (26) compare the relative wage bill for non-production and production workers in region $r$ to the value in a base region within each industry $j$. This is a 'difference in differences' specification with a number of attractive statistical properties. Any industry- 
specific determinant of relative wage bills that is common across regions is 'differenced-out' when we normalize relative to the base region on the lefthand side of the equations (for example, features of the production technology, compensating differentials across industries, other inter-industry wage differentials, and industry-specific labour market institutions such as the degree of unionization). The analysis thus explicitly controls for observed and unobserved heterogeneity in the determinants of relative wage bills across industries.

Similarly, in both region $r$ and the base region we analyze the wage bill of non-production workers relative to production workers. Therefore, any region-specific determinant of wage bills that is common to both nonproduction and production workers is 'differenced-out' when we construct a region's relative wage bill $\left(R W B_{r j}^{N P}=\right.$ wage $\operatorname{bill}_{r j}^{N} /$ wage $\left.\operatorname{bill}_{r j}^{P}\right)$. Here potential examples include neutral regional technology differences and compensating differentials across regions.

\section{Empirical Results}

\subsection{Baseline Specification}

We begin by presenting the estimation results using the UK as a whole as the base region. We first report the results for Administrative Regions, followed by those for Postcode Areas. Table 2 reports the estimated differences in log relative wage bill ratios for Administrative Regions in 1992 and 1986. In 1992 at the 5\% significance level, we find one rejection above zero (for the South-East of England) and 5 rejections below zero (for the East Midlands, Yorkshire \& Humberside, Northern, Wales, and Scotland). The results for 1986 display a similar pattern. At the $5 \%$ significance level, we again find a rejection above zero for the South-East of England, and there are again 5 rejections below zero, with the West Midlands replacing the East Midlands.

Whether a positive estimated value of the dummies corresponds to a higher or lower quality-adjusted relative wage of skilled workers depends on the operator $\Gamma_{j}$ in the cost function (equation 18). With a CES production

technology, a positive coefficient corresponds to a lower quality-adjusted relative skilled wage under a CES production technology if $0<\rho<1$ (see equation 20). These values of $\rho$ imply an elasticity of substitution between 
skilled and unskilled workers greater than unity (i.e. $\sigma>1$ ), which is consistent with typical empirical estimates in the labour literature (see in particular Katz and Autor 1999 and Katz and Murphy 1992).

Table 3 reports implied quality-adjusted relative skilled wages for $\sigma=2$. We find that the skilled-abundant region (here the South-East) is characterized by a lower equilibrium value of the relative wage of skilled workers. The actual wage of non-production workers relative to production workers in the South-East was 97\% of the UK value in 1992 and $99 \%$ in 1986. In both years, this is higher than the estimated quality-adjusted relative wage for $\sigma=2$. This therefore suggests that the relative quality of nonproduction workers in the South-East is higher than in the UK as a whole, as is consistent with economic priors.

Results for Postcode Areas in 1992 and 1986 are presented in Tables 4 and 5. As indicated in the tables, 32 of 111 regions reject factor price equality at the $10 \%$ level in 1992 . Of these, 9 reject above zero and 23 reject below zero. Table 4 reports the estimated dummies for those Postcode Areas that reject above zero. These are concentrated exclusively in the South-East of England close to the M25, M4 corridor, and the area around Cambridge; they include Cambridge, St. Albans, Reading, and Slough (see Figure 3).

Results for 1986 display a similar pattern: 34 regions reject factor price equality at the $10 \%$ level of significance, with 7 rejecting above zero and 27 rejecting below zero. Four of the rejections above zero are the same Postcode Areas as in 1992: Hemel Hempstead, Reading, Slough, and Sutton. The emergence of Cambridge and St. Albans as high relative wage bill regions is specific to 1992 and is consistent with the recent development of a cluster of skill intensive information technology and biotechnology industries in this area.

Tables 4 and 5 also report implied quality adjusted relative wages for $\sigma=2$. Figures 2 and 3 display the geographical distribution of the estimated coefficients for Administrative Regions and Postcode Areas respectively in 1992. The figures separate three groups of regions - those with positive and statistically estimated values of the dummies (indicated by the dark shading); those with negative and statistically significant estimated values of the dummies (corresponding to the intermediate shading); and those with statistically insignificant estimated values of the dummies (light 
or no shading). Both figures show a clear concentration of regions with positive estimated values of the dummies in the South-East of England, where, for $\sigma>1$, the (quality-adjusted) skill premium is relatively low.

We also allow each Administrative Region and each Postcode Area to serve as the base and then run the bilateral regression specified in equation (23). Given the large number of coefficients the bilateral regressions generate, we report a summary of rejections by region definition in Table $6 .^{5}$ For all choices of the base, for both Administrative Regions and Postcode Areas, and in both 1992 and 1986, the null hypothesis that the estimated coefficients on the regional dummies are equal to zero is easily rejected at the $1 \%$ level with a F-test. For Postcode Areas in 1992, $17 \%$ of the regionpairs reject relative factor price equality at the $10 \%$ level, while $11 \%$ reject at the $5 \%$ level. Every region rejects with at least 6 other regions. In $1986,19 \%$ of the region pairs reject relative factor price equality at the $10 \%$ level, and $12 \%$ reject at the $5 \%$ level. Every region rejects with at least 5 other regions at the $10 \%$ level. For Administrative Regions, we find that $57 \%$ of region-pairs reject at the $10 \%$ level in 1992 and $40 \%$ in 1986. This corresponds to an average number of rejections against 5 and 4 Administrative Regions respectively, making clear that the rejection of RFPE is not simply driven by the South-East of England. Every region rejects with at least 2 other regions at the $10 \%$ level in both years.

Taken together, the UK base and the bilateral regression results emphatically reject the null hypothesis of relative factor price equality in the UK.

\subsection{Robustness}

These results are robust across a variety of econometric specifications and to a number of dataset refinements, reported in Table 7. To conserve space, we highlight robustness with respect to the 1992 Administrative Region results. However, similar checks for 1986 Administrative Regions and for Postcode Areas display the same robustness.

The first column of Table 7 reports the baseline results for factor price equality across Administrative Regions in 1992. The baseline sample for

\footnotetext{
${ }^{5}$ Overall, there are 90 and 12,210 possible bilateral rejections for Administrative Regions and Postcode Areas respectively. Any single base region can reject up to 9 or 110 other regions for Administrative Regions and Postcode Areas, respectively.
} 
these results includes all establishments, some of which may report on plants in more than one Administrative Region or Postcode Area. We therefore undertake the following two robustness tests. First, in column (2) we report coefficient estimates for the sub-sample of single plant establishments where overlap does not occur and where we find a very similar pattern of results. Second, in column (3), we allocate establishment-level data to plants on the basis of their shares of establishment employment. All plants associated with an establishment are given the same relative wages and relative wage bills. This robustness test introduces a bias against rejecting RFPE. However, even with this bias, we continue to find a rejection, with the South-East coefficient positive and statistically significant and the Northern, Wales, and Scotland coefficients negative and statistically significant.

The baseline sample includes the population of establishments with more than 100 employees and a sample of establishments with fewer than 100 employees. In order to ensure that our results are not being driven by the presence of a non-random sample of smaller establishments, column (4) also reports results separately for the population of establishments with more than 100 employees. Finally, our coefficient estimates are means across all 4-digit industries in each region. Although each region has a large number of establishments across all industries, some individual industries within a region may contain few establishments. Since measurement error at the establishment level is a potential concern, column (5) also reports estimation results dropping all 4-digit region-industries that contain fewer than 5 establishments. Once again RFPE is rejected and we find a similar pattern of estimated coefficients.

The rejection of relative factor price equality in the UK is an extremely robust empirical finding. In the next Section we explore a number of potential explanations for these results.

\section{Explanations}

\subsection{Multiple Heckscher-Ohlin Cones}

The existence of multiple Heckscher-Ohlin cones of diversification within the UK provides a potential true rejection of relative factor price equality. This rejection is based the immobility of at least one factor, which prevents 
regional factor prices (and endowments) from converging towards a common value across the country. ${ }^{6}$ As noted above, a central prediction of the Heckscher-Ohlin model is that the skill premium is inversely proportional to regional skill endowments across cones (see for example Leamer 1995). Graphically, this relationship is apparent in Figure 1, where the slope of the isocost line anchoring unit value isoquants is steeper in the relatively skill abundant cone.

Our estimates of quality-adjusted relative wages in Table 3 exhibit just such a violation of factor price equality: for reasonable estimates of the elasticity of substitution between production and non-production workers, we find the skill premium to be lower in the regions around London, where skilled labour is relatively abundant, and higher in outlying areas, where skilled labour is relatively scarce.

The potential existence of multiple cones of diversification within the UK is quite important for formulating public policy, in that it implies asymmetric sensitivity of regions to external shocks. A decline in the price of unskilled labour intensive products on world markets (associated with decreases in tariffs and transport costs, or economic growth of labour abundant economics like China) affects workers differently depending upon their region. Such price declines drive down the return to unskilled workers in low-skill regions while unskilled workers in high-skill regions benefit unambiguously from cheaper imports.

A key empirical prediction of multiple Heckscher-Ohlin cones is that regions will exhibit systematic differences in production structure, with skilled abundant regions producing a set of goods that is more skilled intensive than that in unskilled abundant regions.

\subsection{Region-Industry Productivity Differences, Transport Costs and In- creasing Returns}

Region-industry variation in total factor productivity (TFP) can also lead to a true rejection of relative factor price equality. If technology is not common across regions and varies differentially across industries, relative factor prices will vary so long as workers cannot re-locate to arbitrage

\footnotetext{
${ }^{6}$ Cameron and Muellbauer (1998) and Hugues and McCormick (1994) provide empirical evidence on limited labour mobility within the United Kingdom.
} 
away wage differences. Thus, this explanation, though having a different cause than the multiple cone Heckscher-Ohlin explanation, nevertheless relies upon a similar assumption of factor immobility.

To explain our empirical finding of a lower quality-adjusted skill premium in relatively skill abundant regions, it would have to be the case that technical efficiency is systematically relatively higher in low-skill intensive industries within high-skill abundant regions. This is because an increase in technical efficiency of low-skill industries acts like an increase in the relative price of the low-skill goods. Within the simple two factor, two good Heckscher-Ohlin framework, this increase in the price of the low-skill good reduces the quality-adjusted skill premium (via a clockwise rotation of the isocost line), inducing a switch toward more skill intensive techniques in both sectors.

Though this explanation yields an additional empirical prediction, it seems implausible that technical efficiency is higher in skill scarce industries within skill abundant regions. If anything, considerations of knowledge spillovers and external economies of scale appear to suggest that technical efficiency is higher in skill intensive industries disproportionately located in skilled abundant regions.

A conceptually similar violation of relative factor price equality is possible via industry-region variation in transport costs. Indeed, lower transport costs for low-skill industries within skill-abundant regions can lead to the pattern of relative wages observed above.

Geography can also play a role in a true rejection of relative factor price equality via the existence of increasing returns to scale (see Appendix A). To match the skill premia we observe, increasing returns to scale can be either internal or external, but must reduce relative (average) costs of production of low-skill industries in high-skill regions. This region variation in scale economies raises the relative demand for low-skill workers (in the skill-abundant regions) and reduces the skill premium. Here, too, however, we find the existence of this pattern of increasing returns to be implausible. This hypothesis is testable empirically, either indirectly using measured TFP or directly by examining the relative wages of skilled workers and the scale of production in a region. 


\subsection{Spatial Variation in Nominal But Not Real Wages}

Relative wage bills can vary systematically across regions even with perfect labour mobility. If real consumption wages are equal in each region for both types of workers, then workers have no incentive to relocate. Nominal wages may still vary due to differences in the regional cost of living associated with non-traded goods or variation in amenities. For relative wage bills to differ, the cost of living must vary differentially for skilled and unskilled workers across regions. In particular, to explain our finding of a lower relative skilled wage in the South-East, the relative cost of living must be lower there for skilled workers.

This hypothesis also involves a true rejection of RFPE. It implies differential variation in the cost of living for skilled and unskilled workers and empirically testable. The hypothesis predicts the same variation in production structure as in the multiple cone Heckscher-Ohlin model. Industries that are intensive in skilled workers should locate in the region with the lower nominal relative wage for skilled workers, as firms care only about their production costs and not the consumption wage of different types of workers.

\subsection{Heterogeneous products}

The existence of heterogeneous products within industries can lead to a spurious rejection of RFPE. Suppose that relative factor prices are equal across all regions, but there are products with different skill requirements within each industry. If a region systematically produces products that are intensive in skilled labour (in every industry) then its relative wage bill will be larger than the average for the country even without differences in relative (or absolute) factor prices. Thus product heterogeneity can generate a rejection of RFPE but it has to exhibit a particular systematic pattern. Our analysis, by examining wage variation at the four-digit industry level, is a substantial improvement over existing inter- and intra-national studies based upon a coarser aggregation of products and exploits the most disaggregated data currently available data. Furthermore, when restricting the sample to establishments with similar characteristics (e.g. single ver-

sus multi-plant or small versus large establishments), we continue to find a similar pattern of results. 


\section{5. $\quad$ Misclassified workers}

Finally, we note that while our analysis can account for unobserved differences in the quality of non-production and production workers within region-industry pairs, it is susceptible to systematic errors in assigning workers to these job categories. Random misclassification across industryregion pairs and systematic misreporting within an industry is accounted for in our methodology. However, systematic misclassification across regions (e.g. all industries in region $r$ report non-production workers as production workers) can induce spurious rejection of relative factor price equality. While job misclassification may occur, we think it unlikely that all industries in a region will systematically misclassify workers in the same way.

\section{Conclusions}

We examine the extent of relative wage variation across geographic areas of the United Kingdom using a methodology that is robust to unobserved region-industry differences in factor quality, variations in production functions across industries and Hicks-neutral regional technology differences. Despite the United Kingdom being a small, densely-populated country with highly integrated goods markets and the potential for factor mobility, there is strong evidence against absolute and relative wage equality. We find statistically significant and quantitatively important differences in quality-adjusted absolute and relative wages across both broadly defined Administrative Regions as well as more narrowly defined Postcode Areas.

We find that skill abundant regions in the South-East have a lower skill premium than skill scarce regions for plausible values of the elasticity of substitution between skilled and unskilled workers, We examine a number of potential explanations for this finding and highlight additional, empirically verifiable implications of each. Multiple Heckscher-Ohlin cones of diversification and spatial variation in workers' relative cost of living provide natural explanations for the observed variation in skill premia and have the same implications for production structure across regions of the UK. Other explanations based on TFP differences, increasing returns to scale, and transport costs require implausible assumptions to be made. More for-

mal testing of the relative importance of each explanation is an interesting area for further research but lies beyond the scope of this paper. 
Taken together, our findings suggest that variation in relative factor prices plays an important role in shaping firms' location decisions within the UK. The results contribute to our understanding of regional variation in economic outcomes within the UK, an issue of increasing policy-interest in the context of the ongoing process of political devolution. 


\section{References}

Berman, E., Bound, J., Machin, S., (1998) Implications of Skill-biased Technological Change: International Evidence. Quarterly Journal of Economics, November, 1245-79.

Bernard, A. B. and Schott, P. K. (2001) 'Factor Price Equality and the Economies of the United States', Tuck School of Business and Yale School of Management, mimeograph, http://mba.tuck.dartmouth.edu/pages/faculty/andrew.bernard/fpi108.pdf.

Bernstein, J and Weinstein, D (2002) 'Do Endowments Determine the Location of Production? Evidence from National and International Data', Journal of International Economics, 56(1), 55-76.

Cameron, G and Muellbauer, J (1998) 'The Housing Market and Regional Commuting and Migration Costs', Scottish Journal of Political Economy, 45(4), 420-46.

Cameron, C and Muellbauer, J (2000) 'Earnings Biases in the UK Regional Accounts: Some Economic Policy and Research Implications', Economic Journal, vol. 110, no. 464, pp. F412-F429

Cameron, C and Muellbauer, J (2001) 'Earnings, Unemployment, and Housing in Britain', Journal of Applied Econometrics, vol. 16, 3, pp. 203-220.

Ciccone, A (2001) 'Technology Diffusion and the Spatial Distribution of Wages in the US', University of Pompeu Fabra, mimeograph.

Ciccone, A and Hall, R (1996) 'Productivity and the Density of Economic Activity', American Economic Review, 86(1), 54-70.

Cunat, A (2001) 'Can International Trade Equalize Factor Prices?', London School of Economics, mimeograph.

Davis, D, Weinstein, D, Bradford, S, and Shimpo, K (1997) 'Using International and Japanese Regional Data to Determine When the Factor Abundance Theory of Trade Works', American Economic Review, 87(3), 421-46. 
Debaere, P and Demiroglu, U (1997) 'On the Similarity of Country Endowments and Factor Prize Equalization', University of Texas, mimeograph.

Devereux, M, Griffith, R, and Simpson, H (1999) 'The Geographic Distribution of Productive Activity in the UK', Institute for Fiscal Studies Working Paper, W99/26.

Disney, R, Haskel, J, and Heden, Y (2000) 'Restructuring and Productivity Growth in UK Manufacturing', CEPR Discussion Paper, 2463.

Duranton, G and Monastiriotis, V (2001) 'Mind the Gaps: The Evolution of Regional Earnings Inequalities in the UK', Journal of Regional Science, forthcoming.

Duranton, G and Overman, H (2002) 'Localisation in UK Manufacturing Industries: Assessing Non-Randomness using Micro-Geographic Data', CEPR Discussion Paper, 3379.

Gosling, A, Machin, S, and Meghir, C (1996) 'What Has Happened to the Wages of Men since 1996', in (ed) Hills, J, New Inequalities: The Changing Distribution of Income and Wealth in the United Kingdom, Cambridge University Press: Cambridge.

Griffith, R (1999) 'Using the ARD Establishment-level Data to Look at Foreign Ownership and Productivity in the United Kingdom', Economic Journal, 109, F416-F442.

Hanson, G (1998) 'Market Potential, Increasing Returns, and Geographic Concentration', NBER Working Paper, 6429.

Hanson, G and Slaughter, M (2002) 'Labor Market Adjustment in Open Economies: Evidence From U.S. States', Journal of International Economics, forthcoming.

Haskel, J and Slaughter, M (2001) 'Trade, Technology, and UK Wage Inequality', Economic Journal, 111, 163-87.

HM Treasury and DTI (2001) 'Productivity in the UK: 3 - The Regional Dimension', London. http://www.hmtreasury.gov.uk/mediastore/otherfiles/REGIONAL_POLICY.pdf 
Hugues, G and McCormick, B (1994) 'Did Migration in the 1980s Narrow the North-South Divide', Economica, 61, 509-27.

Katz, L and Autor, D (1999) 'Changes in the Wage Structure and Earnings Inequality', in (eds) Ashenfelter, O and Card, D, Handbook of Labor Economics, Vol 3A, North-Holland, 1463-1555.

Katz, L and Murphy, K (1992) 'Changes in Relative Wages, 1963-1987: Supply and Demand Factors', Quarterly Journal of Economics, 107(1), 35-78.

Lawrence, R and Slaughter, M (1993) 'International Trade and American Wages in the 1980s: Giant Sucking Sound or Small Hiccup ?', Brookings Papers on Economic Activity, 2, 161-210.

Leamer, E (1995) The Heckscher-Ohlin Model in Theory and Practice, Princeton Studies in International Finance, 77, February, Department of Economics, Princeton University.

Leontief, W (1953) 'Domestic Production and Foreign Trade: The American Capital Position Re-examined', Proceedings of the American Philosophical Society, 97, 332-49.

Lerner, A (1952) 'Factor Prices and International Trade', Economica, 19(1), $1-15$.

Machin, S (1996) 'Wage Inequality in the UK', Oxford Review of Economic Policy, 12, 47-64.

Machin, S., Van Reenen, J., (1998) Technology and Changes in Skill Structure: Evidence from Seven OECD Countries. Quarterly Journal of Economics, November, 1215-44.

Repetto, A and Ventura, J (1998) 'The Leontief-Trefler Hypothesis and Factor Price Insensitivity', MIT, mimeograph.

Schott, P (2001a) 'One Size Fits All? Heckscher-Ohlin Specialization in Global Production', NBER Working Paper, 8244. 
Schott, P (2001b) 'Do Rich and Poor Countries Specialize in a Different Mix of Goods? Evidence from Product-Level US Trade Data', NBER Working Paper, 8492.

Trefler, D (1993) 'International Factor Price Differences: Leontief was Right!', Journal of Political Economy, 101(6), 961-87. 


\section{A Appendix A}

\section{A1. Imperfect Competition}

This section discusses in more detail the case of imperfect competition. Each of the tests of absolute and relative factor price equality is robust to allowing firms to choose prices subject to a downward sloping demand curve under conditions of imperfect competition. All the tests require is that firms minimize costs. To see this, note that firms' profit maximization problem (1) may be re-written as follows,

$$
\max _{Y_{r j}} \quad \pi_{r j}=v_{r j}\left(Y_{r j}\right) Y_{r j}-A_{r j}^{-1} \Gamma_{j}\left(w_{r}^{P}, w_{r}^{N}, w_{r}^{K}\right) Y_{r j} .
$$

where $B_{r j}=A_{r j}^{-1} \Gamma_{j}\left(w_{r}^{P}, w_{r}^{N}, w_{r}^{K}\right) Y_{r j}$ is the total cost function. The firstorder condition for profit-maximization is,

$$
\frac{d v_{r j}\left(Y_{r j}\right)}{d Y_{r j}} Y_{r j}+v_{r j}\left(Y_{r j}\right)-\frac{\Gamma_{j}(\cdot)}{A_{r j}}=0 .
$$

assuming that the demand function $v_{r j}\left(Y_{r j}\right)$ is invertible and noting that the elasticity of demand is $\varepsilon_{r j}\left(Y_{r j}\right) \equiv-\left(d Y_{r j} / d v_{r j}\right) v_{r j} / Y_{r j}$, we obtain the standard result that equilibrium price is a constant mark-up over marginal cost,

$$
v_{r j}\left(Y_{r j}\right)=\left(\frac{\varepsilon_{r j}\left(Y_{r j}\right)}{\varepsilon_{r j}\left(Y_{r j}\right)-1}\right) \frac{\Gamma_{j}(\cdot)}{A_{r j}} .
$$

By Shepherd's Lemma, equilibrium demand for each quality-adjusted factor of production continues to be given by the derivative of the total cost function with respect to the price of a factor of production as specified in equation (6). Our tests for both relative and absolute factor price equalization may derived in exactly the same way as in the main text.

\section{A2. External Economies of Scale}

It is straightforward to introduce external economies of scale into the framework above in either perfectly or imperfectly competitive market structures. External economies of scale correspond to the assumption that technical efficiency in a region-industry is a function of scale. In the most general case, we have,

$$
A_{r j}=A_{r j}\left(Y_{r j}, Y_{r,-j}, Y_{-r, j}, Y_{-r,-j}\right)
$$


where $Y_{r,-j}$ is the vector of outputs in all other industries in a region, $Y_{-r, j}$ is the vector of all other regions outputs in the industry, and $Y_{-r,-j}$ is the vector of all other regions outputs in all other industries.

External economies of scale provide an explanation for variation in technical efficiency across countries and industries. In order for all production in an industry not to concentrate in a single region, we require either that external economies of scale operate across regions or there to be transport costs. The derivation of the tests for both relative and absolute factor price equality remains exactly as in the main text. The region-industry variation in technical efficiency induced by external economies of scale supplies a potential explanation for violations of absolute and relative factor price equality as discussed in the main text.

\section{A3. Internal Economies of Scale}

Internal economies must clearly be combined with imperfect competition and modify the discussion above in so far as the cost function is no longer linearly homogenous of degree 1 in output. An individual firm $i$ 's profit maximization problem takes the form,

$$
\max _{Y_{i}} \quad v_{i}\left(Y_{i}\right) Y_{i}-A_{r j}^{-1} \Gamma_{j}\left(w_{r}^{P}, w_{r}^{N}, w_{r}^{K}, Y_{i}\right)
$$

where $B_{i}=A_{r j}^{-1} \Gamma_{j}\left(w_{r}^{P}, w_{r}^{N}, w_{r}^{K}, Y_{i}\right)$ is the total cost function. The firm's equilibrium price continues to be a constant mark-up over marginal cost,

$$
v_{i}\left(Y_{i}\right)=\left(\frac{\varepsilon_{i}\left(Y_{i}\right)}{\varepsilon_{i}\left(Y_{i}\right)-1}\right) \frac{1}{A_{r j}} \frac{\partial \Gamma_{j}\left(w_{r}^{P}, w_{r}^{N}, w_{r}^{K}, Y_{i}\right)}{\partial Y_{i}}
$$

Equilibrium demands for quality-adjusted factors of production may again be obtained using Shepherd's Lemma. Using the relationship between quality-adjusted and non-quality adjusted values, a firm's relative demand for observed production and non-production workers will be given by,

$$
\frac{\tilde{N}_{i}}{\tilde{P}_{i}}=\frac{\theta_{r j}^{P}}{\theta_{r j}^{N}} \frac{\partial \Gamma_{j}\left(w_{r}^{P}, w_{r}^{N}, w_{r}^{K}, Y_{i}\right) / \partial w_{r}^{N}}{\partial \Gamma_{j}\left(w_{r}^{P}, w_{r}^{N}, w_{r}^{K}, Y_{i}\right) / \partial w_{r}^{P}}
$$

Multiplying the expressions for observed relative factor prices and observed relative employments, the terms in unobserved factor quality will again cancel. The expression for relative wage bills now becomes, 


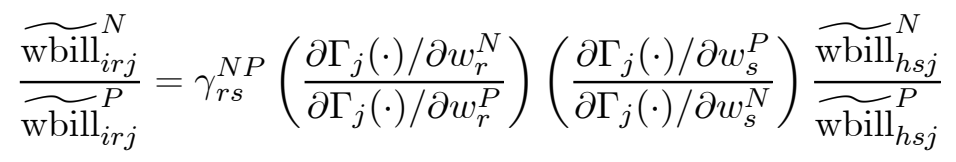

In the standard benchmark case in the theoretical literature on trade under internal economies of scale, firms within an industry face the same constant elasticity of substitution $\varepsilon_{j}$, cost functions are identical and homothetic within industries, and there is free entry so that price equals average cost. Combining free entry with the pricing relationship in (32), the equilibrium

ratio of average to marginal cost will equal a constant $\varepsilon_{j} /\left(\varepsilon_{j}-1\right)$, which with homothetic cost functions defines a unique equilibrium value of output for all firms in the industry $Y_{i}=\bar{Y}_{j}$.

Under the null hypothesis of factor price equalization, $\gamma_{r s}^{N P}=1$ and with all firms in the industry facing the same factor prices and producing the same output the terms in parentheses in (34) will cancel, so that we again obtain the prediction that relative wage bills are equalized under the null.

More generally in the presence of internal economies of scale, variation in firm size across regions and industries provides an additional explanation for violations of relative and absolute factor price equality. For the relative price of skilled workers to be lower in skilled abundant regions, we require firm size to be relatively larger in unskilled intensive industries in skilled abundant regions.

\section{A4. CES Technology}

In this section of the appendix, we consider the special case of a CES production technology. In this case, relative wage bill ratios under the alternative of non-RFPE depend only on relative quality-adjusted wages and the elasticity of substitution between factors of production. In the empirical analysis, this enables us to extract from the estimated coefficients implied differences in quality-adjusted wages across regions. 


\section{A4.1. Profit Maximization}

With a CES production technology, it proves tractable to work directly with the firm's profit maximization problem,

$$
\begin{aligned}
\max _{P, N, K} \quad \Pi_{r j}=v_{r j} A_{r j}[ & \left.a_{j}^{P} P_{r j}^{\rho_{j}}+a_{j}^{N} N_{r j}^{\rho_{j}}+a_{j}^{K} K_{r j}^{\rho_{j}}\right]^{\frac{1}{\rho_{j}}} \\
& -w_{r}^{P} P_{r j}-w_{r}^{N} N_{r j}-w_{r}^{K} K_{r j}
\end{aligned}
$$

where for simplicity we consider the case where firms are price-takers in

product markets. The first-order conditions to this maximization problem are,

$$
\begin{aligned}
& w_{r}^{P}=v_{r j} A_{r j} \rho_{j} a_{j}^{P} P_{r j}^{\rho_{j}-1} Y_{r j}^{1-\rho_{j}} \\
& w_{r}^{N}=v_{r j} A_{r j} \rho_{j} a_{j}^{N} N_{r j}^{\rho_{j}-1} Y_{r j}^{1-\rho_{j}} \\
& w_{r}^{K}=v_{r j} A_{r j} \rho_{j} a_{j}^{N} K_{r j}^{\rho_{j}-1} Y_{r j}^{1-\rho_{j}}
\end{aligned}
$$

where $P_{r j}=\theta_{r j}^{P} \tilde{P}_{r j}, N_{r j}=\theta_{r j}^{N} \tilde{N}_{r j}$, and $K_{r j}=\theta_{r j}^{K} \tilde{K}_{r j}$. From the first-order conditions, observed (non quality-adjusted) relative employment levels of non-production and production workers must satisfy,

$$
\frac{\tilde{N}_{r j}}{\tilde{P}_{r j}}=\frac{\theta_{r j}^{P}}{\theta_{r j}^{N}}\left(\frac{a_{j}^{N}}{a_{j}^{P}}\right)^{1 /\left(1-\rho_{j}\right)}\left(\frac{w_{r}^{N}}{w_{r}^{P}}\right)^{-1 /\left(1-\rho_{j}\right)}
$$

\section{A4.2. Null Hypothesis}

Under the null hypothesis of RFPE, we again obtain the prediction that the ratio of the observed wage bills of non-production to production workers is equalized across regions (this follows immediately from combining equation 12 with equation 39, noting that under RFPE $\left.w_{r}^{N} / w_{r}^{P}=w_{s}^{N} / w_{s}^{P}\right)$ :

$$
\left(H_{0}: \operatorname{RFPE}\right), \quad \frac{\widetilde{\mathrm{wbill}_{r j}^{N}}}{\widetilde{\text { wbill }_{r j}^{P}}}=\frac{\widetilde{\text { wbill }_{s j}^{N}}}{\widetilde{\text { wbill }_{s j}^{P}}}
$$




\section{A4.3. Alternative Hypothesis}

Under the alternative hypothesis of non-RFPE, the observed (nonquality adjusted) relative wages of non-production and production workers in regions $r$ and $s$ are again related according to,

$$
\frac{\tilde{w}_{r}^{N}}{\tilde{w}_{r}^{P}}=\gamma_{r s}^{N P} \frac{\theta_{r j}^{N}}{\theta_{r j}^{P}} \frac{\tilde{w}_{s}^{N}}{\tilde{w}_{s}^{P}}
$$

Using equation (15) with equation (39), relative employment levels in regions $r$ and $s$ under the alternative of non-RFPE are given by,

$$
\frac{\tilde{N}_{r j}}{\tilde{P}_{r j}}=\left(\gamma_{r s}^{N P}\right)^{1 /\left(\rho_{j}-1\right)} \frac{\theta_{r j}^{P}}{\theta_{r j}^{N}} \frac{\tilde{N}_{s j}}{\tilde{P}_{s j}}
$$

Combining equations (41) and (42), we obtain the following prediction for the ratio of the observed wage bills of non-production to production workers:

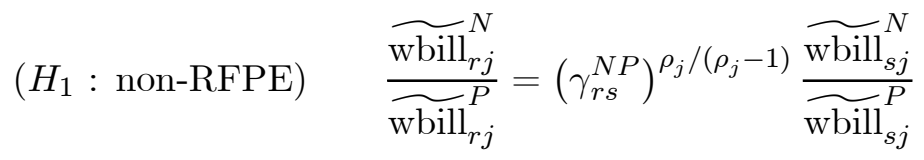

Given estimates of $\left(\gamma_{r s}^{N P}\right)^{\rho_{j} /\left(\rho_{j}-1\right)}$ for $r, s$, if one makes an assumption about the elasticity of substitution between non-production and production workers $\left(\sigma_{j}=1 /\left(1-\rho_{j}\right)\right)$, one can evaluate the relative wage differences across regions implied by the estimates. 


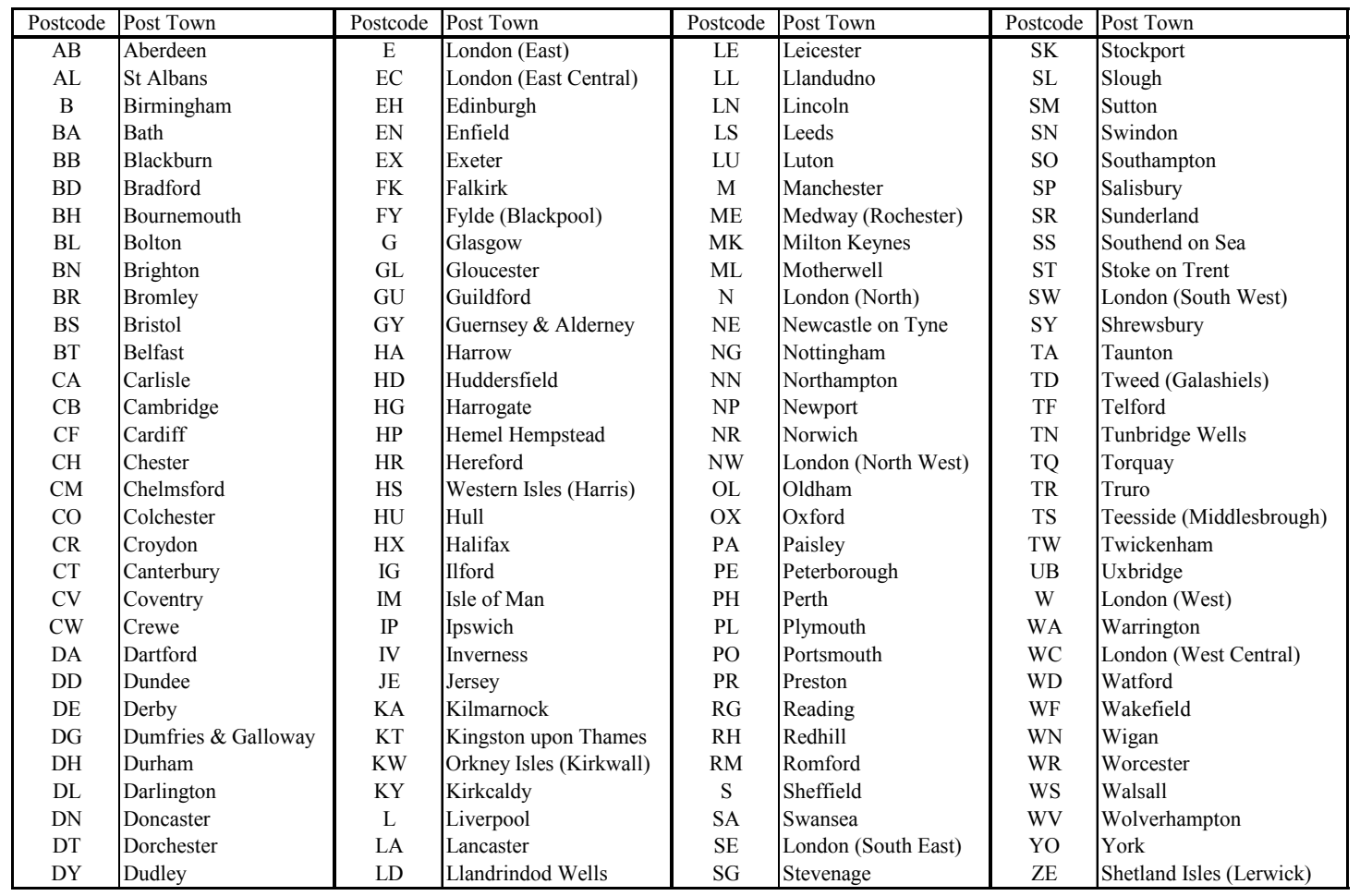

Table 1: Postcode Regions in the UK 


\begin{tabular}{|l|r|r|l|r|r|}
\hline \multicolumn{3}{|c|}{1992} & \multicolumn{3}{|c|}{1986} \\
\hline Administrative & Coeff & p-value & Region & Coeff & p-value \\
\hline South-East & 0.263 & 0.000 & South-East & 0.226 & 0.000 \\
South-West & 0.067 & 0.171 & South-West & -0.072 & 0.123 \\
East Anglia & -0.044 & 0.415 & East Anglia & -0.047 & 0.343 \\
North-West & -0.086 & 0.056 & North-West & -0.044 & 0.290 \\
East Midlands & -0.091 & 0.049 & East Midlands & -0.067 & 0.121 \\
West Midlands & -0.069 & 0.134 & West Midlands & -0.086 & 0.048 \\
Yorkshire & -0.098 & 0.033 & Yorkshire & -0.109 & 0.011 \\
Northern & -0.172 & 0.001 & Northern & -0.309 & 0.000 \\
Wales & -0.187 & 0.000 & Wales & -0.120 & 0.010 \\
Scotland & -0.182 & 0.000 & Scotland & -0.145 & 0.001 \\
\hline F-stat. (p-value) & & 0.000 & F-stat. (p-value) & & 0.000 \\
Observations & & 1440 & Observations & & 1413 \\
\hline
\end{tabular}

Notes: Estimates based on pooling 4 digit industries and regions, taking the UK as a whole as the base region.

Table 2: Estimation Results, Administrative Regions, UK Base

\begin{tabular}{|l|r|l|r|}
\hline \multicolumn{2}{|c|}{1992} & \multicolumn{2}{c|}{1986} \\
\hline Administrative & $\sigma=2$ & Administrative & $\begin{array}{r}\sigma=2 \\
\text { Region }\end{array}$ \\
$\rho=0.5$ & Region & 0.5 \\
\hline South-East & 0.77 & South-East & 0.80 \\
South-West & 0.94 & South-West & 1.05 \\
East Anglia & 1.05 & East Anglia & 1.07 \\
North-West & 1.09 & North-West & 1.12 \\
East Midlands & 1.10 & East Midlands & 1.07 \\
West Midlands & 1.07 & West Midlands & 1.04 \\
Yorkshire & 1.10 & Yorkshire & 1.09 \\
Northern & 1.19 & Northern & 1.36 \\
Wales & 1.21 & Wales & 1.13 \\
Scotland & 1.20 & Scotland & 1.16 \\
\hline
\end{tabular}

Notes: Coefficients used to evaluate relative wage differences are from Table 1, based on pooling 4 digit industries and regions, taking the UK as a whole as the base region.

Table 3: Implied Quality-Adjusted Relative Wage Differences (CES Technology) 


\begin{tabular}{|l|r|r|l|r|r|}
\hline \multicolumn{5}{|c|}{ Positive and Significant Region Coefficients at the 10\% Level } \\
\hline \multicolumn{2}{|c|}{1992} & $\sigma=2$ & \multicolumn{2}{c|}{1986} & $\sigma=2$ \\
Postcode Region & Coeff & $\rho=0.5$ & Postcode Region & Coeff & $\rho=0.5$ \\
\hline Slough & 0.195 & 0.82 & Reading & 0.187 & 0.83 \\
Twickenham & 0.236 & 0.79 & Enfield & 0.201 & 0.82 \\
Swindon & 0.237 & 0.79 & Guildford & 0.208 & 0.81 \\
Hemel Hempstead & 0.244 & 0.78 & Swindon & 0.283 & 0.75 \\
Kingston & 0.247 & 0.78 & Slough & 0.303 & 0.74 \\
Redhill & 0.271 & 0.76 & Hemel Hempstead & 0.311 & 0.73 \\
Cambridge & 0.298 & 0.74 & Sutton & 0.623 & 0.54 \\
St Albans & 0.364 & 0.69 & & & \\
Sutton & 0.559 & 0.57 & & & 0.00 \\
\hline F-stat. (p-value) & & 0.00 & F-stat. (p-value) & & 5027 \\
Observations & & 5044 & Observations & & \\
\hline
\end{tabular}

Notes: Coefficients based on pooling 4 digit industries and postcode areas, taking the UK as a whole as the base region. Listed regions have statistically significant positive coefficients at the $10 \%$ level.

Table 4: Postcode Areas With Positive and Significant Coefficients, UK Base 


\begin{tabular}{|c|c|c|c|c|c|}
\hline \multicolumn{6}{|c|}{ Negative and Significant Region Coefficients at the $10 \%$ Level } \\
\hline \multicolumn{3}{|c|}{1992} & \multicolumn{3}{|c|}{1986} \\
\hline Postcode Region & Coeff & $\begin{array}{r}\sigma=2 \\
\rho=0.5\end{array}$ & Postcode Region & Coeff & $\begin{array}{r}\sigma=2 \\
\rho=0.5\end{array}$ \\
\hline Llandrindod Wells & -0.669 & 1.95 & Dumfries & -0.504 & 1.66 \\
\hline Dumfries & -0.530 & 1.70 & Aberdeen & -0.433 & 1.54 \\
\hline Chester & -0.432 & 1.54 & Cleveland & -0.366 & 1.44 \\
\hline Galashiels & -0.392 & 1.48 & Sunderland & -0.364 & 1.44 \\
\hline Watford & -0.364 & 1.44 & Plymouth & -0.330 & 1.39 \\
\hline Sunderland & -0.357 & 1.43 & Blackpool & -0.327 & 1.39 \\
\hline Exeter & -0.350 & 1.42 & Cardiff & -0.322 & 1.38 \\
\hline Llandudno & -0.344 & 1.41 & Kilmarnock & -0.319 & 1.38 \\
\hline Aberdeen & -0.322 & 1.38 & Truro & -0.306 & 1.36 \\
\hline Peterborough & -0.285 & 1.33 & Newcastle & -0.296 & 1.34 \\
\hline Plymouth & -0.282 & 1.33 & Llandudno & -0.293 & 1.34 \\
\hline Durham & -0.260 & 1.30 & Canterbury & -0.276 & 1.32 \\
\hline Doncaster & -0.249 & 1.28 & Darlington & -0.273 & 1.31 \\
\hline Cleveland & -0.239 & 1.27 & Wolverhampton & -0.252 & 1.29 \\
\hline Sheffield & -0.236 & 1.27 & Wakefield & -0.251 & 1.29 \\
\hline Kilmarnock & -0.234 & 1.26 & Halifax & -0.245 & 1.28 \\
\hline Cardiff & -0.221 & 1.25 & Bradford & -0.231 & 1.26 \\
\hline Crewe & -0.218 & 1.24 & Bath & -0.220 & 1.25 \\
\hline Walsall & -0.197 & 1.22 & Sheffield & -0.210 & 1.23 \\
\hline Dudley & -0.190 & 1.21 & Wigan & -0.208 & 1.23 \\
\hline Manchester & -0.171 & 1.19 & Motherwell & -0.207 & 1.23 \\
\hline Wolverhampton & -0.167 & 1.18 & Oldham & -0.200 & 1.22 \\
\hline Newport & -0.152 & 1.16 & Nottingham & -0.188 & 1.21 \\
\hline & & & Carlisle & -0.185 & 1.20 \\
\hline & & & Walsall & -0.185 & 1.20 \\
\hline & & & Hull & -0.181 & 1.20 \\
\hline & & & Dudley & -0.174 & 1.19 \\
\hline F-stat. (p-value) & & 0.00 & F-stat. (p-value) & & 0.00 \\
\hline Observations & & 5044 & Observations & & 5027 \\
\hline
\end{tabular}

Notes: Coefficients based on pooling 4 digit industries and postcode areas, taking the UK as a whole as the base region. Listed regions have statistically significant negative coefficients at the $10 \%$ level.

Table 5: Postcode Areas With Positive and Significant Coefficients, UK Base 


\begin{tabular}{|c|c|c|c|c|c|}
\hline & \multicolumn{2}{|c|}{$\begin{array}{c}\text { Fraction of All Region-Pairs } \\
\text { Rejecting FPE }\end{array}$} & \multicolumn{2}{|c|}{$\begin{array}{c}\text { Distribution of Rejections } \\
\text { Across All Base Regions at the } \\
10 \% \text { Level of Significance }\end{array}$} \\
\cline { 2 - 6 } Region Definition & $\begin{array}{c}\text { 5\% Level of } \\
\text { Significance }\end{array}$ & $\begin{array}{c}10 \% \text { Level of } \\
\text { Significance }\end{array}$ & Minumim & Mean & Maximum \\
\hline $\begin{array}{c}\text { Administrative Regions } \\
1992\end{array}$ & 0.46 & 0.57 & 2 & 5 & 9 \\
1986 & 0.37 & 0.40 & 2 & 4 & 9 \\
$\begin{array}{c}\text { Postcode Areas } \\
1992\end{array}$ & 0.11 & 0.17 & 6 & 19 & 50 \\
1986 & 0.12 & 0.19 & 5 & 22 & 74 \\
\hline
\end{tabular}

Notes: Bilateral regressions use each region, in turn, as a base region in testing for factor price equality. These regressions analyze wage bills across 4 digit industries in 10 Adminstrative Regions and 111 Postcode Areas. The first two columns report the share of rejections out of the total number of possible rejections. Total possible bilateral rejections are 90 and 12,210 for Administrative Regions and Postcode Areas, respectively. The final three columns given the minimum, mean and maximum number of rejections for each base region. Total possible rejections for each base region are 9 and 110 for Administrative Regions and Postcode Areas, respectively.

Table 6: Bilateral Region-Pair Rejections 


\begin{tabular}{|l|r|r|r|r|r|}
\hline & $(1)$ & $(2)$ & $(3)$ & $(4)$ & \multicolumn{1}{c|}{$(5)$} \\
\hline Administrative & & & At Least 5 \\
Region & & $\begin{array}{r}\text { Single Plant } \\
\text { Establishments }\end{array}$ & $\begin{array}{r}\text { Estimation } \\
\text { Results }\end{array}$ & $\begin{array}{r}\text { Establishments } \\
\text { with }>100 \\
\text { employees }\end{array}$ & $\begin{array}{r}\text { Establishments Per } \\
\text { Region-Industry }\end{array}$ \\
\hline South-East & $0.263 *$ & $0.200 *$ & $0.232 *$ & $0.280 *$ & $0.256 *$ \\
South-West & 0.067 & $0.115 *$ & 0.005 & -0.013 & 0.015 \\
East Anglia & -0.044 & 0.049 & 0.055 & 0.062 & -0.053 \\
North-West & -0.086 & -0.049 & -0.015 & -0.076 & -0.072 \\
East Midlands & $-0.091 *$ & -0.043 & -0.035 & -0.086 & -0.030 \\
West Midlands & -0.069 & -0.060 & -0.063 & $-0.120 *$ & -0.056 \\
Yorkshire & $-0.098 *$ & -0.059 & -0.037 & $-0.094 *$ & -0.074 \\
Northern & $-0.172 *$ & $-0.129 *$ & $-0.101 *$ & $-0.214 *$ & $-0.347 *$ \\
Wales & $-0.187 *$ & $-0.133 *$ & $-0.103 *$ & $-0.227 *$ & $-0.196 *$ \\
Scotland & $-0.182 *$ & $-0.214 *$ & $-0.129 *$ & $-0.161 *$ & $-0.151 *$ \\
\hline F-stat. (p-value) & 0.000 & 0.000 & 0.000 & 0.000 & 0.000 \\
Observations & 1440 & 1317 & 1551 & 1309 & 593 \\
\hline
\end{tabular}

Notes: * denotes statistical significance at the 5\% level. Column (1) reports results from Table 1. Column (2) reports results based upon a sample of single plant establishments. Column (3) reports results where establishment-level data are allocated to plants on the basis of their shares of establishment employment. Column (4) reports results for the population of establishments with more than 100 employees. Column (5) reports results where region-industry pairs are excluded if they have fewer than five establishments.

Table 7: 1992 Administrative Region Coefficients For Various Specifications 


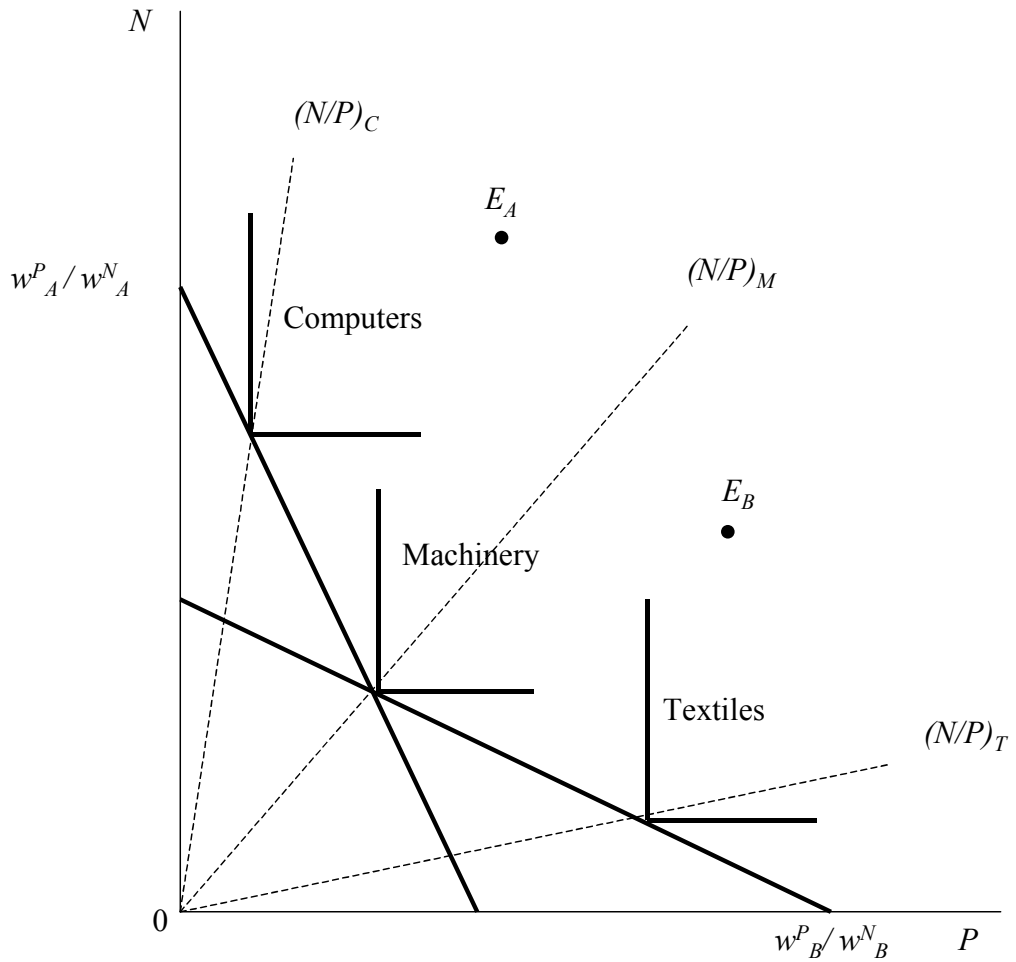

Figure 1: Multiple Cones of Diversification 


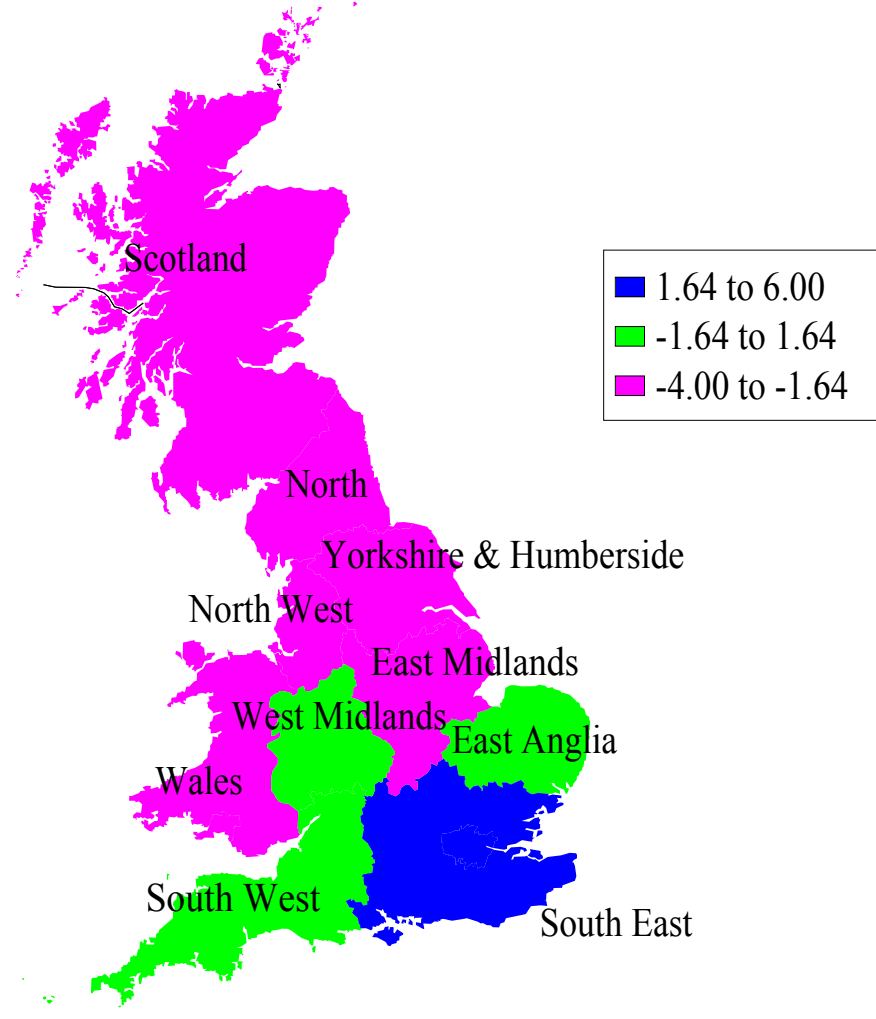

Figure 2: Administrative Region Estimates, 1992 
$199210 \%$

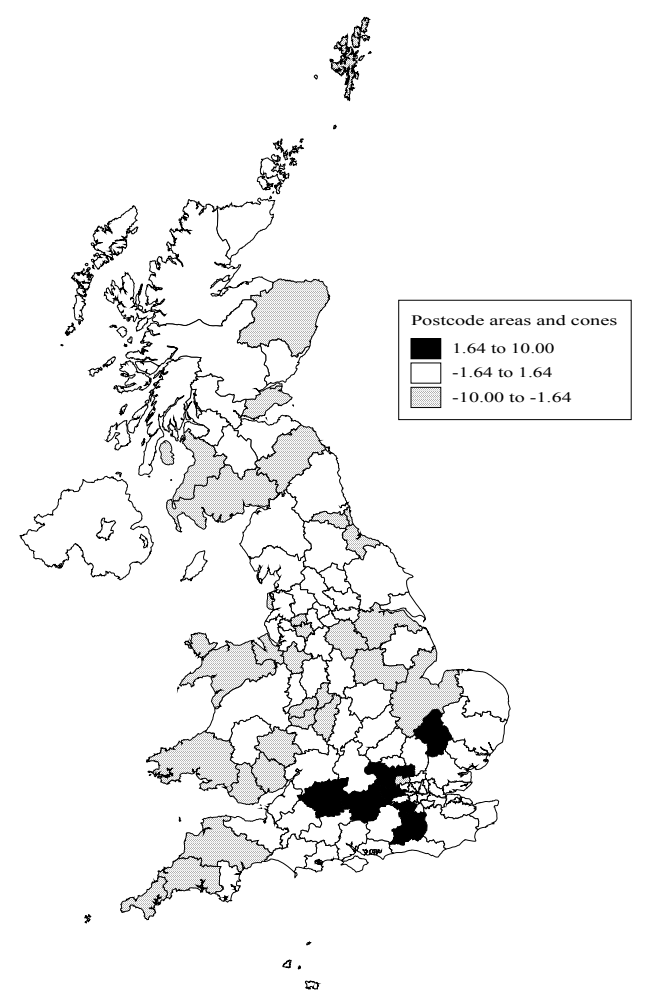

Figure 3: Postcode Area Estimates, 1992 